\title{
Influence of $\mathrm{Gd}^{3+}$ doping concentration on the properties of $\mathrm{Na}(\mathrm{Y}, \mathrm{Gd})$ $\mathrm{F}_{4}: \mathrm{Yb}^{3+}, \mathrm{Tm}^{3+}$ upconverting nanoparticles and their long-term aging behavior
}

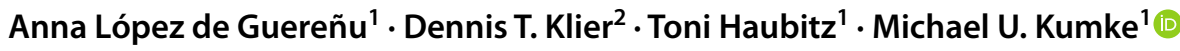

Received: 14 January 2021 / Accepted: 17 December 2021 / Published online: 9 January 2022

(c) The Author(s) 2022

\begin{abstract}
We present a systematic study on the properties of $\mathrm{Na}(\mathrm{Y}, \mathrm{Gd}) \mathrm{F}_{4}$-based upconverting nanoparticles (UCNP) doped with $18 \%$ $\mathrm{Yb}^{3+}, 2 \% \mathrm{Tm}^{3+}$, and the influence of $\mathrm{Gd}^{3+}\left(10-50 \mathrm{~mol} \% \mathrm{Gd}^{3+}\right)$. UCNP were synthesized via the solvothermal method and had a range of diameters within 13 and $50 \mathrm{~nm}$. Structural and photophysical changes were monitored for the UCNP samples after a 24-month incubation period in dry phase and further redispersion. Structural characterization was performed by means of X-ray diffraction (XRD), transmission electron microscopy (TEM) as well as dynamic light scattering (DLS), and the upconversion luminescence (UCL) studies were executed at various temperatures (from 4 to $295 \mathrm{~K}$ ) using time-resolved and steady-state spectroscopy. An increase in the hexagonal lattice phase with the increase of $\mathrm{Gd}^{3+}$ content was found, although the cubic phase was prevalent in most samples. The $\mathrm{Tm}^{3+}$-luminescence intensity as well as the $\mathrm{Tm}^{3+}$-luminescence decay times peaked at the $\mathrm{Gd}^{3+}$ concentration of $30 \mathrm{~mol} \%$. Although the general upconverting luminescence properties of the nanoparticles were preserved, the 24-month incubation period lead to irreversible agglomeration of the UCNP and changes in luminescence band ratios and lifetimes.
\end{abstract}

Keywords Upconversion luminescence $\cdot$ Lanthanides $\cdot$ Near infra-red $\cdot$ Ultra-low temperature $\cdot$ Time-resolved spectroscopy

\section{Introduction}

Upconverting nanoparticles (UCNP) have the ability to convert multiple absorbed photons with lower energy (usually in the NIR range) into light with higher energy (NIR, visible or UV) [1, 2]. UCNP have many advantages as luminescent reporters, among which are sharp luminescence bands at tunable wavelengths, a possibility for multicolor imaging, and luminescence lifetimes in the range of tens to hundreds of $\mu \mathrm{s}$, which permits to detect the UCNP with no background interference and to separate from the conventional fluorophores, which usually have lifetimes in the ns range, using time-gated detection schemes. UCNP are

Michael U. Kumke

Kumke@uni-potsdam.de

1 Institute of Chemistry (Optical Sensing and Spectroscopy), University of Potsdam, Karl-Liebknecht-Str. 24-25, 14476 Potsdam, Germany

2 ORAFOL Europe GmbH, Orafolstraße 2, 16515 Oranienburg, Germany further characterized by relatively low toxicity, absence of photoblinking, chemical inertness, large anti-Stokes shifts, and outstanding photostability, which allows them to be detected with very low optical background interference even in complex biological systems such as body fluids [3-6].

The most frequently studied UCNP, up to now, consist of hexagonal or cubic $\mathrm{NaYF}_{4}$ crystal host lattice doped with a combination of $\mathrm{Ln}^{3+}$ ions, usually $\mathrm{Yb}^{3+}$ as a sensitizer and $\mathrm{Er}^{3+}, \mathrm{Tm}^{3+}$, or $\mathrm{Ho}^{3+}$ as activators [7-10]. Many groups have evaluated the influence of size, shape, crystalline phase, and dopant concentrations of UCNP [11-16]. Different procedures and methods to control the size and shape of lanthanide-doped UCNP have been reported, among which is the tuning of $\mathrm{Gd}^{3+}$ concentration. $\mathrm{Gd}^{3+}$ ions replace the usually used $\mathrm{Y}^{3+}$ ions in the crystal lattice of UCNP. Doping of certain amounts of $\mathrm{Gd}^{3+}$ into the crystal lattice seems to increase the prevalence of hexagonal crystal phase of UCNP and to decrease the size of UCNP without negative effects on the upconversion efficiency $[12,17,18]$. However, the influence of the $\mathrm{Gd}^{3+}$ content has been studied mostly in $\mathrm{Yb}^{3+}, \mathrm{Er}^{3+}$ - doped UCNP, and little information has been published for the $\mathrm{Tm}^{3+}, \mathrm{Gd}^{3+}$-co-doped nanoparticles 
[19-24], even though the most prominent $\mathrm{Tm}^{3+}$ emission band $(800 \mathrm{~nm})$ promises potential advantages for bioapplications by fitting into the biooptical window.

Besides the influence of the $\mathrm{Gd}^{3+}$ on the photophysical properties, it also is frequently used as a contrasting agent for magnetic resonance imaging (MRI) studies [25, 26], thus, doping the UCNP with $\mathrm{Gd}^{3+}$ ions offers a possibility for creating multimodal luminescent reporters. For such applications, but also in general for applications in biosensing, the shelf life of the potential probes becomes a critical issue. Stability of $\mathrm{NaYF}_{4}$-based UCNP in water has been studied by several research groups, and anisotropic structural disintegration of the UCNPs over time in aqueous media has been shown [27-30]. Usually, these studies observe the dissolution behavior of UCNP in aqueous buffers within several days, up to a month. To our knowledge, there has not been a published investigation of the storage and aging of UCNP in dry phase over long periods of time. Redispersing them in an organic solvent in combination with a subsequent phase transfer to water, such a storage layout could be an alternative strategy to facilitate an economically required longer shelf life of UCNP.

Taking this into account, we decided to study the effect of various doping concentrations of $\mathrm{Gd}^{3+}$ as well as dry storage over a long period of time on the photophysical properties of $\mathrm{Na}(\mathrm{Y}, \mathrm{Gd}) \mathrm{F}_{4}: \mathrm{Yb}^{3+}, \mathrm{Tm}^{3+} \mathrm{UCNP}$. A standard one-pot thermal decomposition method with oleate as a capping agent was used to synthesize the $\mathrm{Na}(\mathrm{Y}, \mathrm{Gd})$ $\mathrm{F}_{4}: \mathrm{Yb}^{3+}(18 \mathrm{~mol} \%), \mathrm{Tm}^{3+}(2 \mathrm{~mol} \%) \mathrm{UCNP}$ with the content of $\mathrm{Gd}^{3+}$ being 10, 20, 30, 40 or $50 \mathrm{~mol} \%$, respectively [31]. The photophysical properties of the resulting five UCNP samples were investigated to evaluate the influence of $\mathrm{Gd}^{3+}$ content on the photophysical parameters. Moreover, a comparison of structural and photophysical properties of oleatecapped $\mathrm{Na}(\mathrm{Y}, \mathrm{Gd}) \mathrm{F}_{4}: \mathrm{Yb}^{3+}, \mathrm{Tm}^{3+}$ right after synthesis and after 24 months of dry storage has been performed as well.

\section{Results and discussion}

\subsection{Properties and ageing of $\mathrm{Na}(\mathrm{Y}, \mathrm{Gd}) \mathrm{F}_{4}: \mathrm{Yb}^{3+}, \mathrm{Tm}^{3+}$ UCNP}

\subsubsection{Basic characterization}

The crystalline structures of as-synthesized (AS) and 24-month (24 M) UCNP were investigated using X-Ray powder diffraction (XRD) (Fig. 1 top as well as Figures $\mathrm{S} 1-\mathrm{S} 3$ in $\mathrm{SI}$ ). $\mathrm{NaYF}_{4}$ crystals can exist either in cubic (isotropic, or $\alpha$-) or in hexagonal (anisotropic, or $\beta$-) phase. Despite the presence of $\mathrm{Gd}^{3+}$, the raw XRD diffractograms have shown the presence of both phases in all UCNP samples. To separately analyze the content of the two crystal
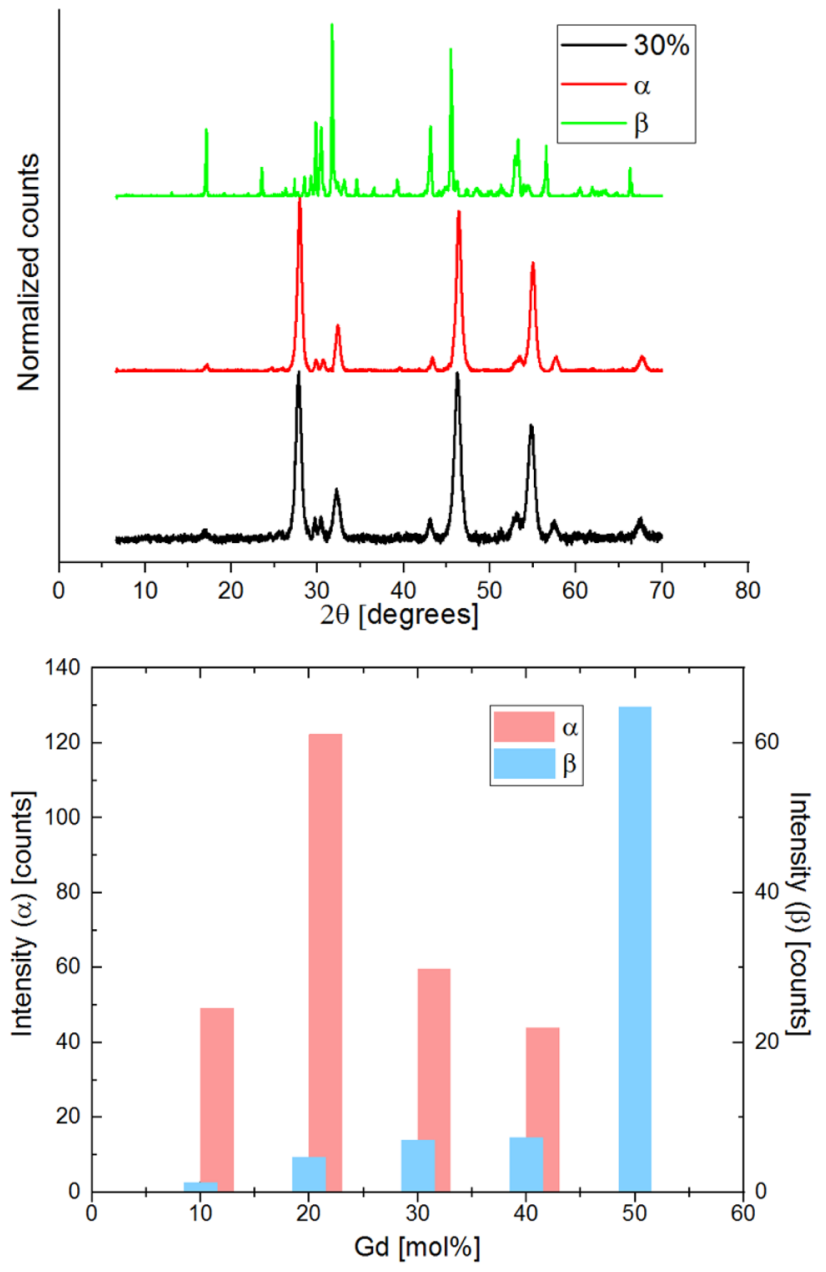

Fig. 1 X-ray powder diffractogram of the $24 \mathrm{M} \mathrm{Na}(\mathrm{Y}, \mathrm{Gd})$ $\mathrm{F}_{4}: \mathrm{Yb}^{3+}, \mathrm{Tm}^{3+}\left(30 \mathrm{~mol} \% \mathrm{Gd}^{3+}\right)$ UCNP with deconvoluted reflexes for the $\alpha$ - and $\beta$-phase using PARAFAC (top). Relative intensities of the cubic- and hexagonal $24 \mathrm{M}$ UCNP lattices calculated from the deconvoluted XRD spectra (bottom)

phases, a Parallel Factor Analysis (PARAFAC) deconvolution algorithm was applied to the raw diffractograms [32]. Besides separating the signals coming from the two different UCNP crystal lattices, it also allowed us to further clear out the signal coming from the $\mathrm{NaCl}$ as a synthesis by-product. From Fig. 1 (bottom) and Figure S3, the quantitative prevalence of the cubic phase can be seen for both AS and $24 \mathrm{M}$ samples. The increase in $\mathrm{Gd}^{3+}$ concentration increased the share of the hexagonal phase in the UCNP. It is widely accepted that the increase in $\mathrm{Gd}^{3+}$ content in the lattice of $\mathrm{NaYF}_{4}$ UCNP leads to the prevalence of the hexagonal crystal structure at high $\mathrm{Gd}^{3+}$ doping concentrations (up to fully replacing $\mathrm{Y}^{3+}$ ions in the lattice) $[9,12,33,34]$. In the investigated sample set the content of the hexagonal lattice distinctly increased at a $\mathrm{Gd}^{3+}$ content of $30 \%$ for the AS samples (see Figure S3). For the $24 \mathrm{M}$ samples (see Fig. 1, 
bottom) a steady increase of the hexagonal phase was found and at $50 \% \mathrm{Gd}^{3+}$ doping only hexagonal phase was present.

The size and shape of the UCNP (AS, $24 \mathrm{M}$ ) were determined by transmission electron microscopy (TEM). An example of the obtained TEM micrographs can be found in Fig. 2, and respective micrographs for all studied samples are shown in Figure S4 and S5. As can be noticed from the images, for AS as well as $24 \mathrm{M}$ samples the nanoparticles could be visually divided into two distinct sub-species in all samples except for the $30 \mathrm{~mol} \% \mathrm{Gd}^{3+}$. The smaller sub-species had a round (or hexagonal) form and was more homogenous in size and shape. The larger sub-species had a shape of a 4-petal flower and was much larger and more heterogeneous in size. In the sample with $30 \mathrm{~mol} \% \mathrm{Gd}^{3+}$, only the "small" sub-species was present, and its diameter was the smallest among all samples (Table 1). The formation of such peculiar petal-like structures could be explained by the growth of a shell with a distinct composition (for example, pure $\mathrm{NaGdF}_{4}$ ) around a core UCNP (which could, for example, consist of cubic-phase $\mathrm{NaYF}_{4}$ ). The content of relative fractions calculated based on the analysis of 200-300 particles on TEM micrographs (small/large sub-species) was in the range of $50 \%$ and did not show any considerable variation in samples with different compositions.

As complementary methods to determine the UCNP sizes, dynamic light scattering (DLS) measurements were conducted, and XRD data on the crystallite size were considered.

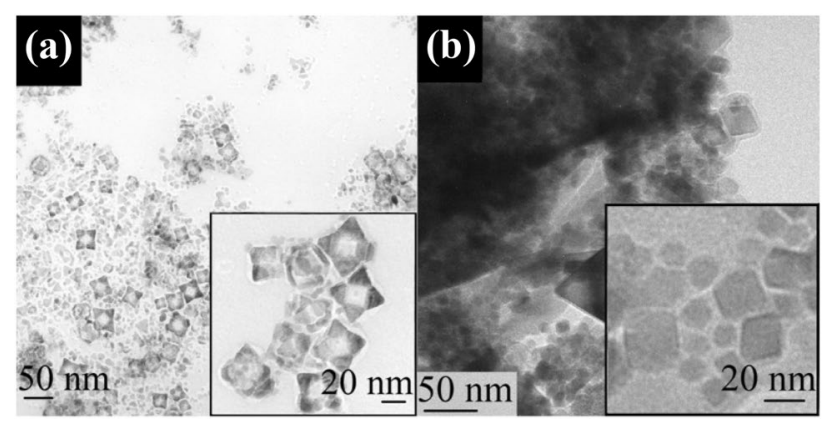

Fig. 2 TEM micrographs of AS (a) and $24 \mathrm{M}$ (b) $\mathrm{Na}(\mathrm{Y}, \mathrm{Gd})$ $\mathrm{F}_{4}: \mathrm{Yb}^{3+}, \mathrm{Tm}^{3+}\left(40 \mathrm{~mol} \% \mathrm{Gd}^{3+}\right)$ UCNP. The scale bars are 50 and $20 \mathrm{~nm}$, respectively (acceleration voltage $200 \mathrm{kV}$ )
From the results presented in Table 1 for AS samples, one can see that, given the margin of error, the crystallite sizes determined by XRD are in good agreement with the sizes of "small" sub-species calculated from TEM micrographs. The sizes determined by DLS appear larger, but it is worth mentioning that the yielding diameters obtained by DLS are hydrodynamic, i.e. they include the solvation shell and the ligand around the particles. In addition the data processing favors the larger particles over the smaller ones, resulting into higher numbers for the particle size on average.

One could also note that the size of the "small" sub-species determined by TEM correlates well with the crystallite size measured by XRD, while the "large" sub-species are similar to the sizes determined by DLS, taking the solvation shell into consideration. This might be a consequence of the "small" sub-species consisting of single crystals, and the "large" ones being multicrystallite, and having more impact on DLS data due to the specifics of the measurement method.

As can be seen from these data, the concentration of $\mathrm{Gd}^{3+}$ ions in nanoparticles did not have a clear relationship with the sizes or crystalline phase content of $\mathrm{Na}(\mathrm{Y}, \mathrm{Gd}) \mathrm{F}_{4}: \mathrm{Yb}^{3+}$, $\mathrm{Tm}^{3+}$ UCNP for the AS samples. The AS sample that was the most homogeneous in size and shape contained $30 \mathrm{~mol} \%$ $\mathrm{Gd}^{3+}$ ions.

Crystalline structures and sizes of the $24 \mathrm{M}$ UCNP were re-assessed using TEM. As shown in Fig. 2b and Figure $\mathrm{S} 5$, there seemed to be more clustering and aggregation of the UCNP compared to the AS samples. The particles still consisted of two fractions: a smaller, more homogenous subspecies and a larger, more diverse in size and shape subspecies, some of which had the four-petal shape, too. The relative content of the large/small sub-species has stayed at approximately $50 \%$ in all five samples, similarly to the AS UCNP.

The data on UCNP sizes obtained from XRD have shown no significant changes in crystallite sizes (Table 1). The sizes obtained from analyzing the XRD data were in good agreement with the diameters calculated from TEM micrographs, and the size of the "small" sub-species corresponded to the crystallite size. Unfortunately, the results of the DLS measurements could not be properly analyzed due to the

Table $1 \mathrm{Na}(\mathrm{Y}, \mathrm{Gd}) \mathrm{F}_{4}: \mathrm{Yb}^{3+}, \mathrm{Tm}^{3+} \mathrm{UCNP}$ diameters (AS and $24 \mathrm{M}$ ), as calculated from TEM micrographs and XRD analyses

\begin{tabular}{|c|c|c|c|c|c|c|c|c|c|c|c|}
\hline \multirow[t]{2}{*}{ Sample } & & \multicolumn{10}{|c|}{ Content of $\mathrm{Gd}^{3+}, \mathrm{mol} \%$ (AS left, $24 \mathrm{M}$ right) } \\
\hline & & 10 & & 20 & & 30 & & 40 & & 50 & \\
\hline \multirow[t]{2}{*}{ Particle size (TEM), nm } & Small & $23 \pm 4$ & $13 \pm 4$ & $23 \pm 4$ & $15 \pm 4$ & $13 \pm 1$ & $13 \pm 4$ & $17 \pm 3$ & $13 \pm 3$ & $23 \pm 6$ & $11 \pm 2$ \\
\hline & Large & $30 \pm 3$ & $28 \pm 3$ & $31 \pm 3$ & $26 \pm 3$ & & & $30 \pm 6$ & $29 \pm 4$ & $42 \pm 9$ & $34 \pm 4$ \\
\hline Crystallite size (XRD), nm & & $21 \pm 3$ & $17 \pm 2$ & $18 \pm 2$ & $16 \pm 2$ & $11 \pm 4$ & $12 \pm 2$ & $16 \pm 2$ & $15 \pm 3$ & $19 \pm 2$ & $16 \pm 3$ \\
\hline Particle size (DLS), nm & & $37 \pm 9$ & - & $38 \pm 11$ & - & $22 \pm 6$ & - & $30 \pm 8$ & - & $50 \pm 8$ & - \\
\hline
\end{tabular}


interference of large UCNP clusters, which appeared over time due to aggregation processes.

\subsection{Upconversion luminescence properties}

The upconversion luminescence (UCL) spectra of oleate - capped $\mathrm{NaYF}_{4}: \mathrm{Yb}^{3+}, \mathrm{Tm}^{3+} \mathrm{UCNP}$ in cyclohexane usually show three prominent luminescence bands centered in 451 $\left({ }^{1} \mathrm{D}_{2} \rightarrow{ }^{3} \mathrm{~F}_{4}\right.$ transition, B1), $481\left({ }^{1} \mathrm{G}_{4} \rightarrow{ }^{3} \mathrm{H}_{6}\right.$ transition, B2), and $800\left({ }^{3} \mathrm{H}_{4} \rightarrow{ }^{3} \mathrm{H}_{6}\right.$ transition, NIR) nm upon excitation

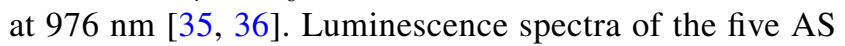
samples were recorded for the three aforementioned luminescence bands. A typical spectrum is shown for the sample with $30 \mathrm{~mol} \% \mathrm{Gd}^{3+}$ (AS and $24 \mathrm{M}$ sample, Fig. 3), (all recorded spectra are shown in the SI, Figure S6).

Comparing absolute intensities of the luminescence spectra between samples usually presents a challenge. To decouple the intensity from the particle concentration and from day-to-day fluctuations of the instrument performance (e.g., laser intensity), the ratio of integral intensities of the emission bands was calculated from the spectra. The band ratio was chosen to analyze the influence of the $\mathrm{Gd}^{3+}$ concentration. When the intensity ratios between the luminescence bands (B1/NIR and B2/NIR) of the UCNP were plotted as a function of the $\mathrm{Gd}^{3+}$ content, a maximum ratio centered at $30 \mathrm{~mol} \%$ was found (Fig. 4). It is tempting to assume that the $\mathrm{B} 1$ band, corresponding to a 4-photon process $\left({ }^{1} \mathrm{D}_{2} \rightarrow{ }^{3} \mathrm{~F}_{4}\right)$, could be the most sensitive to changes in structure of UCNP, while the 3-photon $\mathrm{B} 2\left({ }^{1} \mathrm{G}_{4} \rightarrow{ }^{3} \mathrm{H}_{6}\right)$ and 2-photon NIR $\left({ }^{3} \mathrm{H}_{4} \rightarrow{ }^{3} \mathrm{H}_{6}\right)$ bands are probably better able to withstand variations in these parameters.

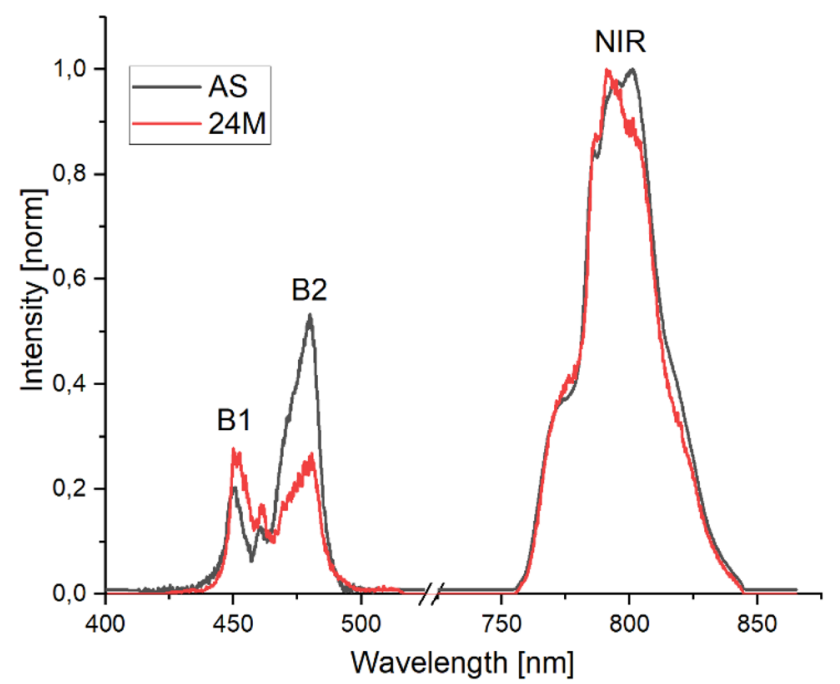

Fig. 3 Upconversion emission intensities of AS and $24 \mathrm{M} \mathrm{Na}(\mathrm{Y}, \mathrm{Gd})$ $\mathrm{F}_{4}: \mathrm{Yb}^{3+}, \mathrm{Tm}^{3+}\left(30 \mathrm{~mol} \% \mathrm{Gd}^{3+}\right)$ UCNP upon pulsed excitation (laser pulse energy $6.6 \pm 0.2 \mathrm{~mJ}$ for AS and $7.1 \pm 0.2 \mathrm{~mJ}$ for $24 \mathrm{M}$ ) at $976 \mathrm{~nm}$. The concentration of UCNP solution was $5 \mathrm{mg} / \mathrm{mL}$
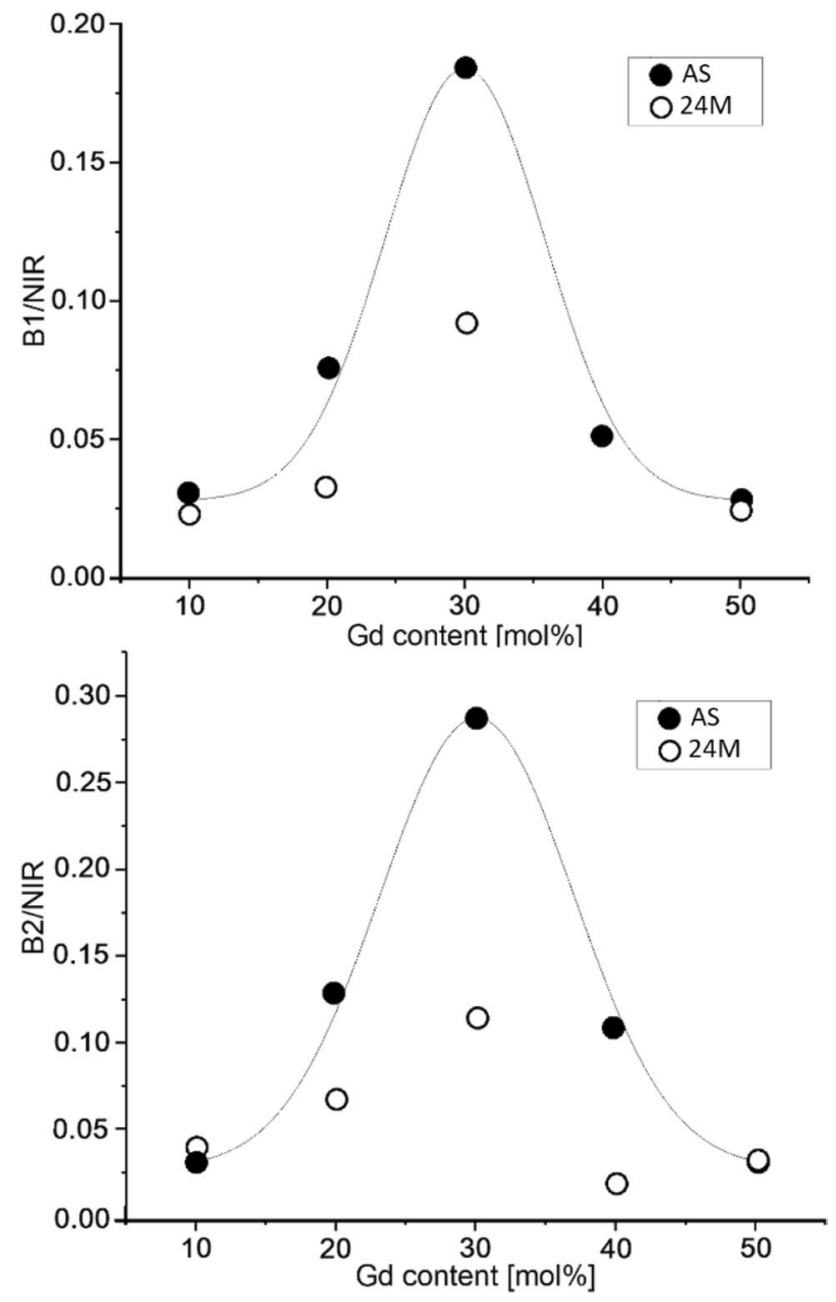

Fig. 4 Intensity ratios of B1/NIR (top) and B2/NIR (bottom) luminescence bands of $\mathrm{Na}(\mathrm{Y}, \mathrm{Gd}) \mathrm{F}_{4}: \mathrm{Yb}^{3+}, \mathrm{Tm}^{3+} \mathrm{UCNP}$ upon excitation at $976 \mathrm{~nm}$

For all $24 \mathrm{M}$ UCNP samples $\left(10-50 \mathrm{~mol} \% \mathrm{Gd}^{3+}\right)$, upconversion luminescence spectra were recorded for the same three luminescence bands. As an example, emission spectra of the sample with $30 \mathrm{~mol} \% \mathrm{Gd}^{3+}$ are shown in Fig. 3 (all spectra are shown in the Supporting Information section, Figure S7).

Also, for the $24 \mathrm{M}$ the shape of the blue band of the $30 \mathrm{~mol} \% \mathrm{Gd}^{3+}$ sample is different from the rest of the samples (Figure S7): the B1 and B2 bands, which correspond to a 4-photon and 3-photon processes, respectively, show much higher intensity than the rest of the samples (Figure S7).

The higher luminescence intensities observed in the samples doped with $30 \% \mathrm{Gd}^{3+}$ could be attributed to higher size/ shape homogeneity of these samples, and the presence of two sub-species in the rest of the samples could possibly negatively influence their luminescence properties.

When the intensity ratios of $\mathrm{B} 1\left({ }^{1} \mathrm{D}_{2} \rightarrow{ }^{3} \mathrm{~F}_{4}\right)$, or $\mathrm{B} 2$ $\left({ }^{1} \mathrm{G}_{4} \rightarrow{ }^{3} \mathrm{H}_{6}\right)$ bands to the NIR $\left({ }^{3} \mathrm{H}_{4} \rightarrow{ }^{3} \mathrm{H}_{6}\right)$ were compared in 
24-month and in as-synthesized UCNP, a drop was observed for both band ratios (Fig. 4). This could be explained by the agglomeration and also by the increase in size differences between the larger and smaller sub-species in these samples. The ratios still peaked at $30 \mathrm{~mol} \%$. The $10 \mathrm{~mol} \%$ and $50 \mathrm{~mol} \%$ samples have shown the least difference between the as-synthesized and 24-month samples.

\subsection{Luminescence decay kinetics}

Luminescence decay kinetics of the B1, B2 and NIR transitions were studied for all five $\mathrm{Na}(\mathrm{Y}, \mathrm{Gd}) \mathrm{F}_{4}: \mathrm{Yb}^{3+}, \mathrm{Tm}^{3+} \mathrm{UCNP}$ samples (AS as well as $24 \mathrm{M}$ samples) In Fig. 5 the decay kinetics of the AS and $24 \mathrm{M}$ sample containing $30 \mathrm{~mol} \%$ $\mathrm{Gd}^{3+}$ are shown. All UCNP had their lifetimes in the range of tens to hundreds of microseconds (Table 2), which is in good agreement with the data reported in literature for UCNP with similar composition [37, 38]. The data were analyzed using a biexponential decay law (Eq. 3), and the relative fractions (see Fig. 6) $f_{i}$ were calculated using Eq. 4.

The complex decay kinetics (Eq. 3) is commonly explained by the presence of two different populations of $\mathrm{Tm}^{3+}$ ions in the UCNP: i) ions on (or close to) the surface of UCNP are more susceptible to quenching by solvent molecules with high-energy vibrations and due to surface defects, which results in shorter decay times; and ii) $\mathrm{Tm}^{3+}$ ions in the bulk phase of the nanoparticle that are more protected from the mentioned phenomena and subsequently tend to have longer decay times [39, 40].

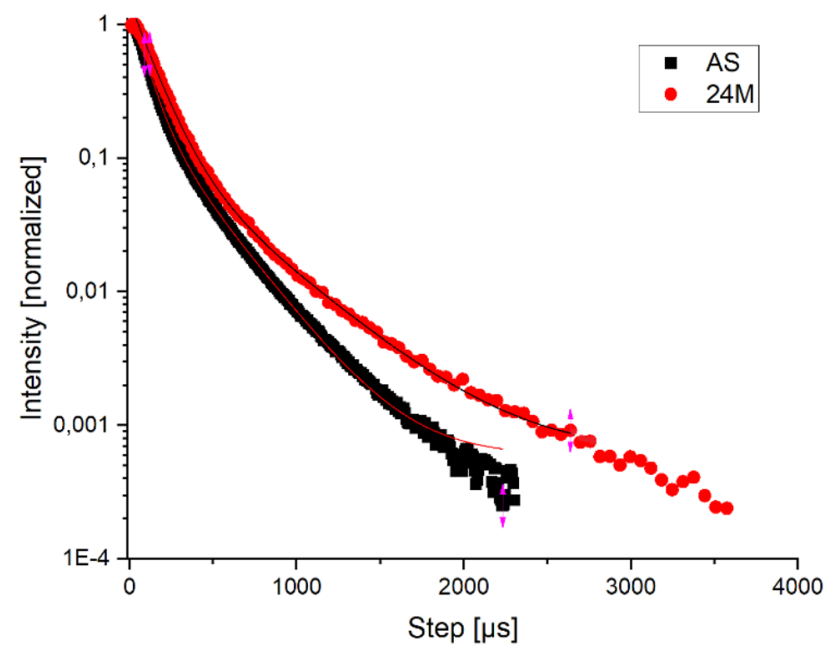

Fig. 5 Normalized UC luminescence decay kinetics of the $\mathrm{Tm}^{3+}$ NIR emission band $(800 \mathrm{~nm})$ of AS (black) and $24 \mathrm{M}$ (red) $\mathrm{Na}(\mathrm{Y}, \mathrm{Gd})$ $\mathrm{F}_{4}: \mathrm{Yb}^{3+}, \mathrm{Tm}^{3+}\left(30 \mathrm{~mol} \%, \mathrm{Gd}^{3+}\right)$ UCNP excited at $976 \mathrm{~nm}$, initial delay $\Delta t=500 \mathrm{~ns}$. The peaks were integrated within the full width at half maximum range. The lines represent the result of the respective data fitting using Eq. (3)

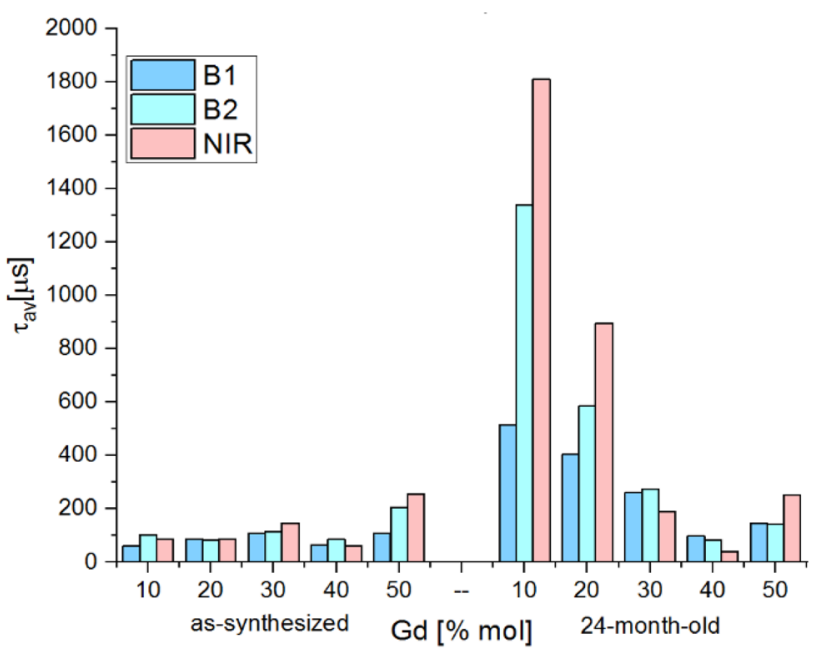

Fig. 6 Average luminescence decay times of AS (left) and $24 \mathrm{M}$ (right) $\mathrm{NaYF}_{4}: \mathrm{Yb}^{3+}, \mathrm{Tm}^{3+}, \mathrm{Gd}^{3+}(30 \mathrm{~mol} \%) \mathrm{UCNP}$

On average for AS UCNP, there was also no linear relationship between luminescence lifetimes and the $\mathrm{Gd}^{3+}$ content, and AS particles with $30 \mathrm{~mol} \%$ of $\mathrm{Gd}^{3+}$ presented relatively longer lifetimes. This is somewhat odd, since their average diameters were the smallest, thus, the higher surface/volume ratio would be expected to facilitate surface-related quenching effects. However, this could probably be counterbalanced by the regularity of the $30 \mathrm{~mol} \% \mathrm{Gd}^{3+}$ — species crystallinity, and, as a result, homogeneity of their size and shape. Thus, the UCNP with $30 \mathrm{~mol} \% \mathrm{Gd}^{3+}$ were the brightest and presented longer luminescence compared to the rest of the UCNP samples.

For 24-month $\mathrm{Na}(\mathrm{Y}, \mathrm{Gd}) \mathrm{F}_{4}: \mathrm{Yb}^{3+}, \mathrm{Tm}^{3+} \mathrm{UCNP}$, luminescence lifetimes have increased in most samples compared to the AS UCNP, especially for the samples with 10 and $20 \mathrm{~mol} \%$ of $\mathrm{Gd}^{3+}$ (Table 2). The changes in surface-to-volume ratios due to the clustering of UCNP could be one reason for these changes. All samples, except the $30 \mathrm{~mol} \% \mathrm{Gd}^{3+}$, still displayed luminescence decay behaviors best fitted by the biexponential decay function, which could also be explained by the regularity and relatively smaller sizes of the $30 \mathrm{~mol} \%$ samples.

Plotting the average decay times $\tau_{\mathrm{av}}$ of the 24-month UCNP as a bar diagram over the $\mathrm{Gd}^{3+}$ content showed a decrease of average decay time with the increase of $\mathrm{Gd}^{3+}$ mol\%, which was opposite to the trend observed in the AS UCNP. However, the absolute values were much higher in the $24 \mathrm{M}$ samples, most likely, due to the agglomeration of the UCNP.

\subsection{Low-temperature upconversion luminescence studies}

We examined the effect of temperature change from 4 to $290 \mathrm{~K}$ on the photoluminescence of the $\mathrm{Na}(\mathrm{Y}, \mathrm{Gd})$ 
Table 2 Luminescence decay times of AS and $24 \mathrm{M}$ $\mathrm{Yb}^{3+}, \mathrm{Tm}^{3+}, \mathrm{Gd}^{3+}$-doped $\mathrm{NaYF}_{4}$ UCNP upon $976 \mathrm{~nm}$ excitation (as calculated from PL decay curves, e.g., in Fig. 5). $\tau_{\mathrm{av}}$ is the average time of luminescence decay calculated according to the Eq. 5

\begin{tabular}{|c|c|c|c|c|c|c|}
\hline \multirow{2}{*}{$\begin{array}{l}\text { Emission band with } \\
\text { respective transition }\end{array}$} & \multirow[t]{2}{*}{$\tau_{\mathrm{av}}, \mu \mathrm{s}$} & \multicolumn{5}{|c|}{ Content of $\mathrm{Gd}^{3+}, \mathrm{mol} \%$} \\
\hline & & 10 & 20 & 30 & 40 & 50 \\
\hline \multirow{2}{*}{$\begin{array}{l}451 \mathrm{~nm} \\
{ }^{1} \mathrm{D}_{2} \rightarrow{ }^{3} \mathrm{~F}_{4} \\
\mathrm{~B} 1\end{array}$} & AS & $61 \pm 9$ & $87 \pm 10$ & $110 \pm 17$ & $66 \pm 12$ & $109 \pm 14$ \\
\hline & $24 \mathrm{M}$ & $516 \pm 15$ & $404 \pm 59$ & $260 \pm 12$ & $98 \pm 18$ & $146 \pm 17$ \\
\hline \multirow{2}{*}{$\begin{array}{l}481 \mathrm{~nm} \\
{ }^{1} \mathrm{G}_{4} \rightarrow{ }^{3} \mathrm{H}_{6} \\
\mathrm{~B} 2\end{array}$} & AS & $102 \pm 6$ & $85 \pm 6$ & $115 \pm 17$ & $87 \pm 14$ & $206 \pm 9$ \\
\hline & $24 \mathrm{M}$ & $1338 \pm 86$ & $585 \pm 47$ & $275 \pm 7$ & $84 \pm 17$ & $142 \pm 13$ \\
\hline $800 \mathrm{~nm}$ & AS & $88 \pm 18$ & $88 \pm 20$ & $147 \pm 40$ & $63 \pm 15$ & $254 \pm 23$ \\
\hline $\begin{array}{l}{ }^{3} \mathrm{H}_{4} \rightarrow{ }^{3} \mathrm{H}_{6} \\
\text { NIR }\end{array}$ & $24 \mathrm{M}$ & $1809 \pm 63$ & $895 \pm 46$ & $191 \pm 24$ & $41 \pm 8$ & $253 \pm 14$ \\
\hline
\end{tabular}

$\mathrm{F}_{4}: \mathrm{Yb}^{3+}, \mathrm{Tm}^{3+} \mathrm{UCNP}$, in order to provide more detailed information on the luminescence and competing nonradiative deactivation processes in UCNP $[12,20]$. As an example, in Fig. 7 one can find emission spectra of $50 \mathrm{~mol} \%$ $\mathrm{Gd}^{3+}$ UCNP for the temperature range of $4 \mathrm{~K}<\mathrm{T}<290 \mathrm{~K}$ $\left(\lambda_{\mathrm{ex}}=976 \mathrm{~nm}\right)$. This pattern of temperature dependence is representative for all the studied UCNP. The intensity of the NIR emission band was usually much higher than B1 or B2 at any given temperature. Luminescence intensities of all three emission bands were lower at room temperature and showed a steady increase with cooling down from 290 to $4 \mathrm{~K}$. These results differ from the data presented in literature for similar studies on $\mathrm{Er}^{3+}$-doped nanoparticles $[12,41]$ : for $\mathrm{NaYF}_{4}: \mathrm{Yb}^{3+}, \mathrm{Er}^{3+} \mathrm{UCNP}$ doped with either different amounts of $\mathrm{Gd}^{3+}$ or $\mathrm{Er}^{3+}$, all samples have shown a maximum point of luminescence intensity in the range of 50-100 K (depending on the doping concentration), followed by a decrease in luminescence intensity.

Normalized luminescence intensities of the blue $(\mathrm{B}=\mathrm{B} 1+\mathrm{B} 2)$ and NIR emission bands for all UCNP species were plotted as a function of temperature (in the range of 4-290 K) (Supporting Information, Figure S8). To further process these data, we used a Boltzmann-type equation [12, 42, 43]:

$R=\frac{I_{B}}{I_{N I R}}=A \exp \left(-\frac{\Delta E}{k_{B} T}\right)$

where $R$ is the ratio of integrated luminescence intensities originating from the respective UCL emission bands, $\Delta E$ is the energy gap separating the process-relevant energy levels, $k_{B}$ is the Boltzmann constant, $T$ is the temperature, and $A$ is a constant which depends on the spontaneous emission rate and the energies of the emitting states of the host material [12].

We plotted the logarithm of UCNP luminescence bands intensity ratios against reciprocal temperature (as an example, B and NIR are shown in Fig. 8), and fitted to calculate the energy gap $\Delta E$ according to Eq. 1. The resulting values of $\Delta E$ for $\mathrm{B} / \mathrm{NIR}$ ratio can be found in Table $\mathrm{S} 1$.
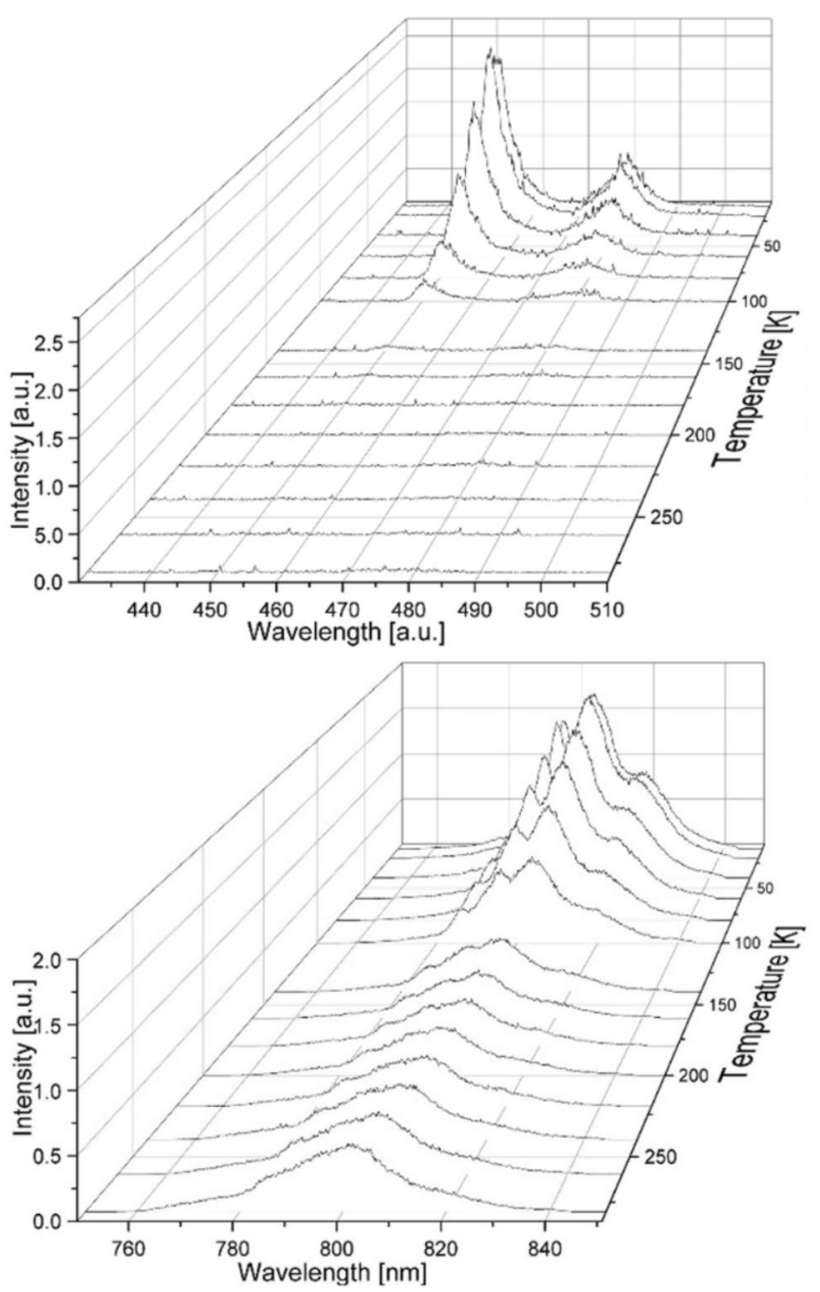

Fig. 7 Temperature-dependent UC emission of AS $\mathrm{Na}(\mathrm{Y}, \mathrm{Gd})$ $\mathrm{F}_{4}: \mathrm{Yb}^{3+}, \mathrm{Tm}^{3+}\left(50 \mathrm{~mol} \% \mathrm{Gd}^{3+}\right)$ UCNP $\left(\lambda_{\mathrm{ex}}=976 \mathrm{~nm}\right)$. Blue (B1) and (B2) (top) and near-infrared (NIR) (bottom) emission bands are shown. A Continuous-wave fiber coupled laser operating at $1 \mathrm{~W}$ was used to record the spectra

The resulting $\Delta \mathrm{E}$ values were within the range of $30-40 \mathrm{~cm}^{-1}$ for all studied samples, and we did not observe any clear influence of $\mathrm{Gd}^{3+}$ content on the energy gap values. 


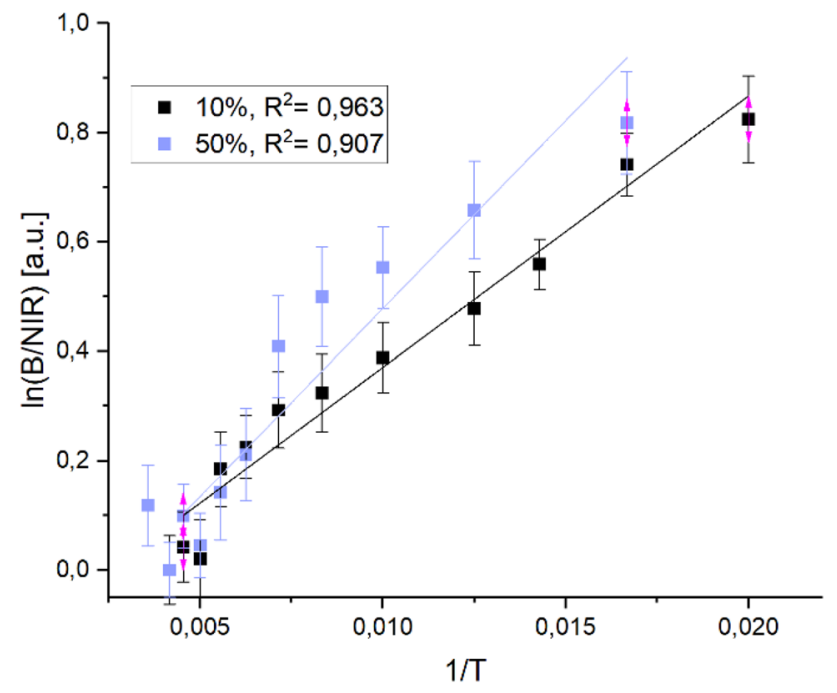

Fig. 8 Analysis of temperature dependence the integrated emission intensity ratio of $\mathrm{B}$ and NIR bands, shown are data for AS$\mathrm{Na}(\mathrm{Y}, \mathrm{Gd}) \mathrm{F}_{4}: \mathrm{Yb}^{3+}, \mathrm{Tm}^{3+}\left(10\right.$ and $\left.50 \mathrm{~mol} \% \mathrm{Gd}^{3+}\right)$

These results can be explained by the following: in $\mathrm{Yb}^{3+}$ the two lowest energy levels of the ${ }^{2} \mathrm{~F}_{5 / 2}$ multiplet are ${ }^{2} \mathrm{~F}_{5 / 2}|0\rangle$ $\left(\sim 10,281 \mathrm{~cm}^{-1}\right)$ and ${ }^{2} \mathrm{~F}_{5 / 2}|1\rangle\left(\sim 10,242 \mathrm{~cm}^{-1}\right)$. The observed emission is determined by both population and excitation cross-section of ${ }^{2} \mathrm{~F}_{5 / 2}|0\rangle$ and ${ }^{2} \mathrm{~F}_{5 / 2}|1\rangle$ levels of $\mathrm{Yb}^{3+}$. The energy difference between the two Stark levels is known from literature to be just $39 \mathrm{~cm}^{-1}[12,44]$.

The experimental values obtained from our calculations ( $\Delta E$ in the range of $34-42 \mathrm{~cm}^{-1}$ ) are an order of magnitude lower than the values of $\Delta E$ reported for the emission of $\operatorname{Er}^{3+}[12,44,45]$, and lower than the expected values for $\mathrm{Tm}^{3+}$ (hundreds to thousands of $\mathrm{cm}^{-1}$ ) [44], but very close to the values of the energy gap of $\mathrm{Yb}^{3+}$. A possible explanation for that is that, unlike in the $\mathrm{Yb}^{3+}-\mathrm{Er}^{3+}$-pair, energy transfer from $\mathrm{Yb}^{3+}$ to $\mathrm{Tm}^{3+}$ is not strongly influenced by the energy levels of $\mathrm{Yb}^{3+}$, as the ${ }^{3} \mathrm{H}_{5}$ energy level of $\mathrm{Tm}^{3+}$ is substantially lower than either ${ }^{2} \mathrm{~F}_{5 / 2}|0\rangle$ or ${ }^{2} \mathrm{~F}_{5 / 2}|1\rangle$ (unlike the ${ }^{4} \mathrm{I}_{11 / 2}$ level of Er) [12]. However, the lower level of the $\mathrm{Yb}^{3+}$ $\left({ }^{2} \mathrm{~F}_{5 / 2}|1\rangle\right)$ seems to be more effective in the sensitization of $\mathrm{Tm}^{3+}$ and therefore, the thermal coupling of the two states is observed. Since the content of $\mathrm{Yb}^{3+}$ in all of the studied UCNP species was kept constant, it also explains why the content of $\mathrm{Gd}^{3+}$ had no effect on the observed $\Delta \mathrm{E}$ values. Thus, we can conclude that, most likely, the energy gap values that we obtained from the experiment could rather be assigned to the excited state of $\mathrm{Yb}^{3+}$ rather than $\mathrm{Tm}^{3+}$.

Average luminescence lifetimes were recorded for all AS UCNP species at 4, 100 and $200 \mathrm{~K}$ and analyzed using a biexponential decay law (Eq. 3). The general trend showed a decrease of luminescence decay times with the increase of temperature (Figure S9). This could be explained by the increase of the contribution of non-radiative processes with temperature due to the increase of the population of vibrationally excited states, resulting in faster deactivation rates at higher temperatures.

\section{Conclusions}

We have synthesized $\mathrm{Na}(\mathrm{Y}, \mathrm{Gd}) \mathrm{F}_{4}: \mathrm{Yb}^{3+}, \mathrm{Tm}^{3+}$ upconverting nanoparticles with different $\mathrm{Gd}^{3+}$-content (10-50 mol\%) via thermal decomposition method and investigated the effect of $\mathrm{Gd}^{3+}$ co-doping on the physical and luminescent properties of the obtained UCNP. For the first time, we have compared these properties of the UCNP sample set shortly after synthesis (as-synthesized, AS) and after 24 months (24 M) of storing in dry phase, providing a "four-dimensional study" of their properties.

The UCNP showed good upconversion luminescence upon $976 \mathrm{~nm}$ pulsed Nd:YAG laser excitation and luminescence lifetimes in the range from tens to hundreds of $\mu$ s both after synthesis and after the incubation period of 24 months. The analysis of XRD data has revealed an increase in the hexagonal ( $\beta$-) lattice phase with the increase of $\mathrm{Gd}^{3+}$ content, although the cubic $(\alpha-)$ phase was prevalent in all samples except the $24 \mathrm{M}$ sample with $50 \mathrm{~mol} \% \mathrm{Gd}^{3+}$. TEM images of the samples revealed the presence of small homogeneous sub-species and larger and more heterogeneous subspecies. Best size and shape regularity was observed at $\mathrm{Gd}^{3+}$ concentration of $30 \mathrm{~mol} \%$, and, hence, the luminescence emission intensity and luminescence decay times of UCNP with this composition were the highest. This differs from the data acquired from similar studies on $\mathrm{Er}^{3+}$-doped UCNP $[12,41]$, where a linear relationship between $\mathrm{Gd}^{3+}$ doping concentration and the prevalence of $\beta$-lattice UCNP was found, resulting in pure hexagonal structures at high $\mathrm{Gd}^{3+}$ concentrations, which improved the photophysical properties of the UCNP. The reason for this inconsistency may lie in another factors, such as synthesis conditions, control over temperature, and/or choice of reaction solvent.

Comparison of the properties of the same $\mathrm{Na}(\mathrm{Y}, \mathrm{Gd})$ $\mathrm{F}_{4}: \mathrm{Yb}^{3+}, \mathrm{Tm}^{3+} \mathrm{UCNP}$ series right after the synthesis (AS) and after 24 months of storage revealed some changes in their upconversion behavior and physical properties. Although the XRD results have shown no significant changes in the crystalline size, the data obtained from TEM have shown an increase in particle size, which could be explained by aggregation. This led to longer decay times and a change in luminescence band ratios in all samples except 10 and $50 \mathrm{~mol} \% \mathrm{Gd}^{3+}$, which have shown the least change in their luminescence band ratios over the 24-month storage time.

Thus, storing UCNP in dry phase and redispersing them in cyclohexane after a long storage period does not seem to be the most optimal way to preserve their properties, despite the conservation of upconversion luminescence in all the 
samples. For the applications where the size and structure of the UCNP and the exact relationship between luminescence bands are of crucial importance, it would be recommendable to turn to other methods of UCNP storage, such as freezing the UCNP in a solution.

\section{Experimental}

\subsection{Chemicals}

Yttrium (III) chloride hexahydrate (99.99\%), gadolinium(III) chloride hexahydrate (99.99\%), thulium (III) chloride hexahydrate $(99.99 \%)$, ammonium fluoride $(\geq 99.0 \%)$, and oleic acid (90\%) were purchased from Sigma-Aldrich, ytterbium(III) chloride hexahydrate $(99.99 \%)$ was purchased from Alfa Aesar, 1-Octadecene ( $\geq 91.0 \%$ ) from Merck, and Sodium hydroxide (99\%) and absolute ethanol were purchased from Carl Roth.

\subsection{Synthesis of oleate-capped $\mathrm{Gd}^{3+}$-doped upconverting nanoparticles}

Upconverting nanoparticles (UCNP) were synthesized by the thermal decomposition method, in which oleic acid (OA) was used as a capping agent and 1-Octadecene was used as a solvent [31]. In this method, lanthanide chlorides are added to a mixture of high boiling octadecene and oleic acid (volume ratio 3:2). To study the influence of different lanthanide ratios, the overall amount of lanthanide ions $\left(\mathrm{Y}^{3+}, \mathrm{Yb}^{3+}\right.$, $\mathrm{Tm}^{3+}$ and $\left.\mathrm{Gd}^{3+}\right)$ was kept constant $(2 \mathrm{mmol})$, while $\mathrm{Y}^{3+}$ ions were replaced by $\mathrm{Gd}^{3+}$ ions. In a typical procedure, $\mathrm{YCl}_{3}$ (30-70 $\mathrm{mol} \%), \mathrm{GdCl}_{3}(10-50 \mathrm{~mol} \%), \mathrm{YbCl}_{3}(18 \mathrm{~mol} \%)$, $\mathrm{TmCl}_{3}(2 \mathrm{~mol} \%), \mathrm{OA}(15.6 \mathrm{ml})$ and 1-Octadecene $(36 \mathrm{ml})$ were mixed together in a $50 \mathrm{ml} 3$-neck flask. After a clear solution was formed, the suspension is gradually heated to $145^{\circ} \mathrm{C}$ under evacuation, which results in generating of $\mathrm{Ln}^{3+}$ oleates, and then cooled down to $45{ }^{\circ} \mathrm{C}$. $\mathrm{NaOH}(0.3 \mathrm{~g})$ and $\mathrm{NH}_{4} \mathrm{~F}(0.2 \mathrm{~g})$ were added to the mixture under a counter stream of argon (Ar), which induced nanocrystal growth, and the solution was stirred until the precipitate dissolved. The reaction mixture was then rapidly heated to $310^{\circ} \mathrm{C}$ min under gentle Ar flow to prevent the oxidation process. At these high temperatures, the process of Ostwald ripening (90 min) leads to the formation of highly crystalline nanoparticles: smaller particles dissolve, which supports the growth of larger particles. Heating was performed using an oil bath and a magnetic stirrer with a heating plate (Heidolph MR Hei-End, Germany) and temperature was controlled using a mercury-in-glass thermometer (Labortherm-N, Germany). Subsequently, the solution was cooled down to room temperature and the resulting UCNP were precipitated in $15 \mathrm{ml}$ of ethanol, centrifuged ( $8000 \mathrm{rpm}$ for $20 \mathrm{~min}$, from
Sigma Laborzentrifugen 2-15, Sigma, Germany) and then washed 3 times with ethanol. Finally, the UCNP were dispersed in $15 \mathrm{~mL}$ of cyclohexane for further use.

\subsection{Ageing of $\mathrm{Gd}^{3+}$-doped Upconverting Nanoparticles}

The five $\mathrm{Na}(\mathrm{Y}, \mathrm{Gd}) \mathrm{F}_{4}: \mathrm{Yb}^{3+}, \mathrm{Tm}^{3+} \mathrm{UCNP}$ samples in cyclohexane were dried and stored at room temperature in the darkness in sealed vessels throughout 24 months. Then, the UCNP were easily redispersed in cyclohexane without any indication for a chemical alteration and their physical and luminescent properties UCNP were assessed.

\subsection{X-ray diffraction}

To study the crystal structure and the phase content of UCNP, X-ray powder diffraction (XRD) patterns were collected using a D5005 instrument (Siemens AG, Munich, Germany) in a range of $3-70^{\circ} / 2 \theta$ with divergence aperture, scattering ray aperture and graphite monochromatized $\mathrm{CuK} \alpha$ radiation $(\lambda=0.15406 \mathrm{~nm})$. The scanning step was $0.02^{\circ} / 2 \theta$ with a counting time of $4 \mathrm{~s}$ per step.

The set of XRD data was deconvoluted into different components of the spectral and concentration domain by the Parallel Factor Analysis (PARAFAC) algorithm [32] implemented in the optimization toolbox of Matlab R2019b. The non-negative constraint was applied to the XRD spectra and concentration dimension.

\subsection{Transmission electron microscopy}

Two transmission electron microscopes were used to estimate the size and morphology of the UCNP. The first one, JEM 1011 transmission electron microscope (Jeol Ltd, Tokyo, Japan) (TEM) using a wolfram hairpin cathode, an accelerating voltage of $80 \mathrm{kV}$ and a molybdenum panel. The measurements were recorded using a side-mounted Olympus Mega View G2 (Olympus Germany GmbH, Hamburg, Germany).

The second microscope used was Tecnai G2 20, from FEI/Thermo Fisher Scientific) at an acceleration voltage of $200 \mathrm{kV}$. Samples were prepared by dropping diluted dispersions on carbon-coated copper grids (400 mesh). Particle counting was performed using ImageSP Viewer software.

\subsection{Dynamic light scattering}

The hydrodynamic diameters of UCNP were determined by dynamic light scattering (DLS) using a Zetasizer Nano ZS (Malvern Instruments Ltd, Herrenberg, Germany) at $25^{\circ} \mathrm{C}$ with a detection angle of $173^{\circ}$. A He-Ne laser at $632.8 \mathrm{~nm}$ with $P=25 \mathrm{~mW}$ was used as a light source. 
To obtain nanocrystal sizes (D) from the X-ray diffractograms, Williamson-Hall equation was used:

$\Delta q(q)=k \cdot \frac{2 \pi}{D}+\varepsilon^{\prime} \cdot q ; q=\frac{4 \pi}{\lambda} \cdot \sin \theta$,

where $D$ is the diameter of the nanocrystallite, $k$ is the shape factor of particle morphology (here 0.9 ), $\lambda$ is the wavelength of the X-ray, $\varepsilon^{\prime}$ corresponds to variations of lattice constant of an infinite number of crystallites, $\theta$ is the Bragg angle of the diffraction peak and $\Delta q$ is the full width at half maximum of the diffraction peaks as a function of $q$. The crystallite size $D$ was obtained from the reciprocal of the intercept: $\boldsymbol{D}=2 \boldsymbol{k} \boldsymbol{\pi} / \boldsymbol{\Delta} \boldsymbol{q}_{0}$.

\subsection{Steady-state and time-resolved upconversion luminescence measurements at room temperature}

Steady state and time resolved upconversion luminescence measurements were carried out at room temperature. The UCNP were excited at $976 \mathrm{~nm}$ using a wavelength tunable pulsed Nd:YAG laser (Quanta Ray, Spectra-Physics, Mountain View, CA) combined with an OPO system (GWULasertechnik Vertriebsges.mbH, Erftstadt, Germany) operating at $10 \mathrm{~Hz}$ as excitation light source. All upconversion luminescence spectra were recorded using an intensified CCD-camera (iStar DH720-18 V-73, Andor Technology, Belfast, Great Britain) coupled to a spectrograph (Shamrock SR 303i, Andor Tehonology, Belfast, Great Britain) equipped with a $600 \mathrm{~L} / \mathrm{mm}$ grating. Time resolved luminescence spectra were recorded by applying a "boxcar" technique in which the amplitude $\boldsymbol{A}_{\boldsymbol{i}}$ is converted to "true amplitude" $\boldsymbol{F}_{\boldsymbol{i}}$ because of the dependence of $\boldsymbol{A}_{\boldsymbol{i}}$ on the detection gate width $\mathbf{t}_{\text {gate }}$ [46]. Equation 2 shows this relation:

$F_{i}=\frac{A_{i}}{\tau_{i}\left(1-\mathrm{e}^{-\frac{\text { tgate }^{-}}{\tau_{i}}}\right)}$

where $\boldsymbol{F}_{\boldsymbol{i}}$ is the coefficient by gate width $\mathbf{t}_{\text {gate }}$ correction, $\boldsymbol{A}_{\boldsymbol{i}}$ is the experimental coefficient (amplitude of the fit function), $\mathbf{t}_{\text {gate }}$ is the detection gate width (duration of the photoluminescence emission recording), and $\tau_{i}$ is the luminescence decay time of the i component. For fitting of recorded luminescence decay curves Eq. 3 was used:

$I(\mathrm{t})=y_{0}+A_{1} \mathrm{e}^{-k_{1} \mathrm{t}}+A_{2} \mathrm{e}^{-k_{2} \mathrm{t}}$

where $\boldsymbol{k}_{\boldsymbol{i}}=\frac{1}{\boldsymbol{\tau}_{i}}$ is the rate constant, $\boldsymbol{I}(\mathbf{t})$ is the luminescence intensity in dependence on timet, $\boldsymbol{y}_{0}$ is the offset of the fitting function and accounts for background signal contribution, and $\tau_{i}$ is the luminescence decay time of the $\mathrm{i}$ component.
The relative fractions $f_{i}$ were calculated using the following equation:

$f_{i}=\frac{F_{i} \tau_{i}}{\sum_{k} F_{k} \tau_{k}}$

The average luminescence decay times were calculated according to this equation:

$\tau_{a v}=\tau_{1} \cdot f_{1}+\tau_{2} \cdot f_{2}$

\subsection{X-ray diffraction}

The temperature-dependent steady-state upconversion luminescence measurements were recorded using a continuous wave fiber coupled laser diode working at $1000 \mathrm{~mW}$ (SHE-SP-975-160-FS-SMA, Laser $2000 \mathrm{GmbH}$, Wessling, Germany) coupled to a shutter to avoid the heating of the sample. In order to perform low-temperature luminescence measurements in a range of $4 \mathrm{~K}<T<293 \mathrm{~K}$, the UCNP colloidal solutions or powders were sealed inside glass tubes and placed on a copper sample holder in a vacuum chamber attached to a cold plate of a closed cycle liquid helium cryostat. The cryostat system consisted of a helium compressor unit (Sumitomo Heavy Industries Ltd., Markt Indersdorf, Germany), a vacuum pump (Leybold vacuum Turbolab 80, Oerlikon, Köln, Germany) for the sample chamber, and a temperature controller (331 temperature controller, Lake Shore, Westerville, $\mathrm{OH}$ ). The excitation light was focused directly on the samples. The upconversion luminescence emission was recorded using a lens system set in front of a fiber connected spectrograph (Shamrock SR-303i, Andor Technology, Belfast, Great Britain) equipped with an intensified CCD camera (iStar DH 72018 V 73, Andor Technology, Belfast, Great Britain).

Supplementary Information The online version contains supplementary material available at https://doi.org/10.1007/s43630-021-00161-4.

Acknowledgements We thank Markus Mildner from Institute of Medical Physics and Biophysics, Charité and Petra Schrade from the Core Facility for Electron Microscopy, Charité for their support with recording the TEM images and Dr Christina Günter for the help with XRD measurements.

Author contributions The authors have contributed equally in the preparation of the manuscript.

Funding Open Access funding enabled and organized by Projekt DEAL. Anna López de Guereñu is grateful for financial funding by the excellence initiative of the German Research Foundation (DFG) School of Analytical Sciences Adlershof (SALSA, project number 8711110399) and the Federal Institute for Materials Research and Testing (BAM). 
Availability of data and materials Additional data can be found in the SI section.

\section{Declarations}

Conflict of interest There are no conflict to declare.

Open Access This article is licensed under a Creative Commons Attribution 4.0 International License, which permits use, sharing, adaptation, distribution and reproduction in any medium or format, as long as you give appropriate credit to the original author(s) and the source, provide a link to the Creative Commons licence, and indicate if changes were made. The images or other third party material in this article are included in the article's Creative Commons licence, unless indicated otherwise in a credit line to the material. If material is not included in the article's Creative Commons licence and your intended use is not permitted by statutory regulation or exceeds the permitted use, you will need to obtain permission directly from the copyright holder. To view a copy of this licence, visit http://creativecommons.org/licenses/by/4.0/.

\section{References}

1. Auzel, F. (2004). Upconversion and anti-stokes processes with $\mathrm{f}$ and d ions in solids. Chemical Reviews, 104, 139-173. https://doi. org/10.1021/cr020357g

2. Hesse, J., Klier, D. T., Sgarzi, M., Nsubuga, A., Bauer, C., Grenzer, J., Hübner, R., Wislicenus, M., Joshi, T., Kumke, M. U., \& Stephan, H. (2018). Rapid synthesis of sub-10 nm hexagonal $\mathrm{NaYF}_{4}$-based upconverting nanoparticles using Therminol ${ }^{\circledR} 66$. ChemistryOpen, 7, 159-168. https://doi.org/10.1002/open.20170 0186

3. Gorris, H. H., Saleh, S. M., Groegel, D. B. M., Ernst, S., Reiner, K., Mustroph, H., \& Wolfbeis, O. S. (2011). Long-wavelength absorbing and fluorescent chameleon labels for proteins, peptides, and amines. Bioconjugate Chemistry, 22, 1433-1437. https://doi. org $/ 10.1021 / \mathrm{bc} 200192 \mathrm{k}$

4. Gorris, H. H., \& Resch-Genger, U. (2017). Perspectives and challenges of photon-upconversion nanoparticles-Part II: Bioanalytical applications. Analytical and Bioanalytical Chemistry, 409, 5875-5890. https://doi.org/10.1007/s00216-017-0499-z

5. Sy, M., Nonat, A., Hildebrandt, N., \& Charbonnière, L. J. (2016). Lanthanide-based luminescence biolabelling. Chemical Communications, 52, 5080-5095. https://doi.org/10.1039/c6cc00922k

6. López de Guereñu, A., Bastian, P., Wessig, P., John, L., \& Kumke, M. (2019). Energy transfer between tm-doped upconverting nanoparticles and a small organic dye with large stokes shift. Biosensors, 9, 9. https://doi.org/10.3390/bios9010009

7. Haase, M., \& Schäfer, H. (2011). Upconverting nanoparticles. Angew. Chemie - Int. Ed., 50, 5808-5829. https://doi.org/10.1002/ anie. 201005159

8. Damasco, J. A., Chen, G., Shao, W., Ågren, H., Huang, H., Song, W., Lovell, J. F., \& Prasad, P. N. (2014). Size-tunable and monodisperse $\mathrm{Tm}^{3+} / \mathrm{Gd}^{3+}$-doped hexagonal $\mathrm{NaYbF}_{4}$ nanoparticles with engineered efficient near infrared-to-near infrared upconversion for in vivo imaging. ACS Applied Materials \& Interfaces, 6 , 13884-13893. https://doi.org/10.1021/am503288d

9. Wang, F., Han, Y., Lim, C. S., Lu, Y., Wang, J., Xu, J., Chen, H., Zhang, C., Hong, M., \& Liu, X. (2010). Simultaneous phase and size control of upconversion nanocrystals through lanthanide doping. Nature, 463, 1061-1065. https://doi.org/10.1038/nature08777
10. Kaiser, M., Würth, C., Kraft, M., Hyppänen, I., Soukka, T., \& Resch-Genger, U. (2017). Power-dependent upconversion quantum yield of $\mathrm{NaYF}_{4}: \mathrm{Yb}^{3+}, \mathrm{E}^{\mathrm{r} 3}+$ nano- and micrometer-sized particles - measurements and simulations. Nanoscale, 9, 1005110058. https://doi.org/10.1039/c7nr02449e

11. Klier, D. T., \& Kumke, M. U. (2015). Analysing the effect of the crystal structure on upconversion luminescence in $\mathrm{Yb}^{3+}, \mathrm{Er}^{3+}$ -co-doped NaYF 4 nanomaterials. Journal of Materials Chemistry C, 3, 11228-11238. https://doi.org/10.1039/C5TC02218E

12. Klier, D., \& Kumke, M. U. (2015). Upconversion luminescence properties of $\mathrm{NaYF}_{4}: \mathrm{Yb}$ : Er nanoparticles codoped with $\mathrm{G}^{\mathrm{d} 3}+$. Journal of Physical Chemistry C, 119, 3363-3373. https://doi. org/10.1021/jp5103548

13. Wisser, M. D., Fischer, S., Maurer, P. C., Bronstein, N. D., Chu, S., Alivisatos, A. P., Salleo, A., \& Dionne, J. A. (2016). Enhancing quantum yield via local symmetry distortion in lanthanidebased upconverting nanoparticles. ACS Photonics, 3, 1523-1530. https://doi.org/10.1021/acsphotonics.6b00166

14. Ma, C., Xu, X., Wang, F., Zhou, Z., Liu, D., Zhao, J., Guan, M., Lang, C. I., \& Jin, D. (2017). Optimal sensitizer concentration in single upconversion nanocrystals. Nano Letters, 17, 2858-2864. https://doi.org/10.1021/acs.nanolett.6b05331

15. Zhou, B., Shi, B., Jin, D., \& Liu, X. (2015). Controlling upconversion nanocrystals for emerging applications. Nature Nanotechnology, 10, 924-936. https://doi.org/10.1038/nnano.2015.251

16. Zhao, J., Lu, Z., Yin, Y., McRae, C., Piper, J. A., Dawes, J. M., Jin, D., \& Goldys, E. M. (2013). Upconversion luminescence with tunable lifetime in $\mathrm{NaYF}_{4}: \mathrm{Yb}$ Er nanocrystals: Role of nanocrystal size. Nanoscale, 5, 944-952. https://doi.org/10.1039/c2nr32482b

17. Zhang, J., Mi, C., Wu, H., Huang, H., Mao, C., \& Xu, S. (2012). Synthesis of $\mathrm{NaYF}_{4}: \mathrm{Yb} / \mathrm{Er} / \mathrm{Gd}$ up-conversion luminescent nanoparticles and luminescence resonance energy transferbased protein detection. Analytical Biochemistry, 83, 1-29. https://doi.org/10. 1158/0008-5472

18. Ostrowski, A. D., Chan, E. M., Gargas, D. J., Katz, E. M., Han, G., Schuck, P. J., Milliron, D. J., \& Cohen, B. E. (2012). Controlled synthesis and single-particle imaging of bright, sub-10 $\mathrm{nm}$ lanthanide-doped upconverting nanocrystals. ACS Nano, 6 , 2686-2692. https://doi.org/10.1021/nn3000737

19. Zhou, B., Yan, L., Tao, L., Song, N., Wu, M., Wang, T., \& Zhang, Q. (2018). Enabling photon upconversion and precise control of donor-acceptor interaction through interfacial energy transfer. Advanced Science. https://doi.org/10.1002/advs.201700667

20. Klier, D. T., \& Kumke, M. U. (2015). Upconversion NaYF 4:Yb: Er nanoparticles co-doped with $\mathrm{Gd}^{3+}$ and $\mathrm{Nd}^{3+}$ for thermometry on the nanoscale. RSC Advances, 5, 67149-67156. https://doi.org/ $10.1039 / \mathrm{c} 5 \mathrm{ra} 11502 \mathrm{~g}$

21. Shi, F., \& Zhao, Y. (2014). Sub-10 nm and monodisperse $\beta-\mathrm{NaYF}_{4}: \mathrm{Yb}, \mathrm{Tm}, \mathrm{Gd}$ nanocrystals with intense ultraviolet upconversion luminescence. Journal of Materials Chemistry C, 2, 2198-2203. https://doi.org/10.1039/C3TC32303J

22. Vidyakina, A. A., Kolesnikov, I. E., Bogachev, N. A., Skripkin, M. Y., Tumkin, I. I., Lähderanta, E., \& Mereshchenko, A. S. (2020). $\mathrm{Gd}^{3+}$-doping effect on upconversion emission of $\mathrm{NaYF}_{4}: \mathrm{Yb}^{3+}$, $\mathrm{Er}^{3+} / \mathrm{Tm}^{3+}$ microparticles. Materials (Basel), 13, 1-12. https:// doi.org/10.3390/ma13153397

23. Li, Y., Yang, L., Li, Y., Yu, S., Yang, P., \& Jiang, F. (2013). Influence of $\mathrm{Ce}^{3+}$ and $\mathrm{Gd}^{3+}$ co-doping on the structure and upconversion emission in hexagonal $\mathrm{Ho} 3+$ doped $\mathrm{NaYbF}_{4}$ phosphors. Ceramics International, 39, 1183-1188. https://doi.org/10.1016/j. ceramint.2012.07.042

24. Han, Y., An, Y., Jia, G., Wang, X., He, C., Ding, Y., \& Tang, Q. (2018). Facile assembly of upconversion nanoparticle-based micelles for active targeted dual-mode imaging in pancreatic cancer. Journal of Nanobiotechnology, 16, 1-13. https://doi.org/10. 1186/s12951-018-0335-4 
25. Ren, W. T., Liang, L. B., Qi, F., Sun, Z. B., Yang, Z. Y., Huang, X. Q., Wu, Q. Z., Zhu, H. Y., Yu, X. F., Quan, H., \& Gong, Q. Y. (2011). Bimodal fluorescence and magnetic resonance imaging using water-soluble hexagonal $\mathrm{NaYF}_{4}: \mathrm{Ce}, \mathrm{Tb}, \mathrm{Gd}$ nanocrystals. Journal of Nanomaterials, 2011, 1-8. https://doi.org/10.1155/ 2011/531217

26. Wen, H. Q., Peng, H. Y., Liu, K., Bian, M. H., Xu, Y. J., Dong, L., Yan, X., Xu, W. P., Tao, W., Shen, J. L., Lu, Y., \& Qian, H. S. (2017). Sequential growth of $\mathrm{NaYF}_{4}: \mathrm{Yb} / \mathrm{Er} @ \mathrm{NaGdF}_{4}$ nanodumbbells for dual-modality fluorescence and magnetic resonance imaging. ACS Applied Materials \& Interfaces, 9, 9226-9232. https://doi.org/10.1021/acsami.6b16842

27. Lisjak, D., Plohl, O., Ponikvar-Svet, M., \& Majaron, B. (2015). Dissolution of upconverting fluoride nanoparticles in aqueous suspensions. RSC Advances, 5, 27393-27397. https://doi.org/10. 1039/c5ra00902b

28. Lisjak, D., Plohl, O., Vidmar, J., Majaron, B., \& Ponikvar-Svet, M. (2016). Dissolution mechanism of upconverting $\mathrm{AYF}_{4}: \mathrm{Yb}, \mathrm{Tm}$ $(\mathrm{A}=\mathrm{Na}$ or $\mathrm{K}$ ) nanoparticles in aqueous media. Langmuir, 32, 8222-8229. https://doi.org/10.1021/acs.langmuir.6b02675

29. Lahtinen, S., Lyytikäinen, A., Päkkilä, H., Hömppi, E., Perälä, N., Lastusaari, M., \& Soukka, T. (2017). Disintegration of hexagonal $\mathrm{NaYF}_{4}: \mathrm{Yb}^{3+}, \mathrm{E}^{\mathrm{r} 3}+$ upconverting nanoparticles in aqueous media: The role of fluoride in solubility equilibrium. Journal of Physical Chemistry C, 121, 656-658. https://doi.org/10.1021/acs.analchem. $5 \mathrm{~b} 02228$

30. Plohl, O., Kraft, M., Kovač, J., Belec, B., Ponikvar-Svet, M., Würth, C., Lisjak, D., \& Resch-Genger, U. (2017). Optically detected degradation of NaYF4:Yb, Tm-based upconversion nanoparticles in phosphate buffered saline solution. Langmuir, 33, 553-560. https://doi.org/10.1021/acs.langmuir.6b03907

31. Liu, Q., Feng, W., \& Li, F. (2014). Water-soluble lanthanide upconversion nanophosphors: synthesis and bioimaging applications in vivo. Coordination Chemistry Reviews, 273-274, 100110. https://doi.org/10.1016/j.ccr.2014.01.004

32. Bro, R. (1997). PARAFAC Tutorial and applications. Chemometrics and Intelligent Laboratory Systems, 38, 149-171. https://doi. org/10.1016/S0169-7439(97)00032-4

33. Chen, F., Bu, W., Zhang, S., Liu, X., Liu, J., Xing, H., Xiao, Q., Zhou, L., Peng, W., Wang, L., \& Shi, J. (2011). Positive and negative lattice shielding effects co-existing in Gd (III) ion doped bifunctional upconversion nanoprobes. Advanced Functional Materials, 21, 4285-4294. https://doi.org/10.1002/adfm.20110 1663

34. Xie, W., An, X., Chen, L., Li, J., Leng, J., Lü, W., Zhang, L., \& Luo, Y. (2017). Tunable phase and upconverting luminescence of $\mathrm{Gd}^{3+}$ co-doped $\mathrm{NaErF}_{4}$ : $\mathrm{Yb}^{3+}$ nanostructures. Materials Research Bulletin, 95, 509-514. https://doi.org/10.1016/j.mater resbull.2017.08.033

35. DaCosta, M. V., Doughan, S., Han, Y., \& Krull, U. J. (2014). Lanthanide upconversion nanoparticles and applications in bioassays and bioimaging: a review. Analytica Chimica Acta, 832, 1-33. https://doi.org/10.1016/j.aca.2014.04.030

36. Maurizio, S. L., Tessitore, G., Mandl, G. A., \& Capobianco, J. A. (2019). Luminescence dynamics and enhancement of the UV and visible emissions of $\mathrm{Tm}^{3+}$ in $\mathrm{LiYF}_{4}: \mathrm{Yb}^{3+}, \mathrm{T}^{\mathrm{m} 3}+$ upconverting nanoparticles. Nanoscale Advances, 1, 4492-4500. https://doi.org/ 10.1039/C9NA00556K

37. Arppe, R., Hyppänen, I., Perälä, N., Peltomaa, R., Kaiser, M., Würth, C., Christ, S., Resch-genger, U., Schäferling, M., \& Soukka, T. (2015). Quenching of the upconversion luminescence of $\mathrm{NaYF}_{4}: \mathrm{Yb}^{3+}, \mathrm{E}^{\mathrm{r} 3}+$ and $\mathrm{NaY}_{\mathrm{F}} 4: \mathrm{Y}^{\mathrm{b} 3}+,{ }^{\mathrm{Tm}} 3+$ nanophosphors by water: the role of the sensitizer ${ }^{\mathrm{Yb}_{3}} 3+$ in non-radiative relaxation. Nanoscale, 7, 11746-11757. https://doi.org/10.1039/c5nr02100f

38. Zhu, X., Zhang, J., Liu, J., \& Zhang, Y. (2019). Recent progress of rare-earth doped upconversion nanoparticles: synthesis, optimization, and applications. Advancement of Science, 6, 1901358. https://doi.org/10.1002/advs.201901358

39. Chen, G., Ågren, H., Ohulchanskyy, T. Y., \& Prasad, P. N. (2015). Light upconverting core-shell nanostructures: nanophotonic control for emerging applications. Chemical Society Reviews, 44, 1680-1713. https://doi.org/10.1039/c4cs00170b

40. Fischer, S., Bronstein, N. D., Swabeck, J. K., Chan, E. M., \& Alivisatos, A. P. (2016). Precise tuning of surface quenching for luminescence enhancement in core-shell lanthanide-doped nanocrystals. Nano Letters, 16, 7241-7247. https://doi.org/10. 1021/acs.nanolett.6b03683

41. Li, L., Zhao, N., Fu, L., Zhou, J., Ai, X., \& Zhang, J. (2018). Temperature modulation of concentration quenching in lanthanide-doped nanoparticles for enhanced upconversion luminescence. Nano Research, 11, 2104-2115. https://doi.org/10.1007/ s12274-017-1828-4

42. Xu, C. T., Zhan, Q., Liu, H., Somesfalean, G., Qian, J., He, S., \& Andersson-Engels, S. (2013). Upconverting nanoparticles for pre-clinical diffuse optical imaging, microscopy and sensing: current trends and future challenges. Laser \& Photonics Reviews, 7, 663-697. https://doi.org/10.1002/lpor.201200052

43. Fischer, L. H., Harms, G. S., \& Wolfbeis, O. S. (2011). Upconverting nanoparticles for nanoscale thermometry. Angewandte Chemie, 50, 4546-4551. https://doi.org/10.1002/anie.201006835

44. Carnall, W. T., Fields, P. R., \& Wybourne, B. G. (1965). Spectral intensities of the trivalent lanthanides and actinides in solution. I. $\mathrm{Pr} 3+, \mathrm{Nd} 3+, \mathrm{Er} 3+, \mathrm{Tm} 3+$, and $\mathrm{Yb} 8+1$. The Journal of Chemical Physics, 42, 3797-3806. https://doi.org/10.1063/1.1695840

45. Gavrilović, T. V., Jovanović, D. J., Lojpur, V., \& Dramićanin, M. D. (2014). Multifunctional $\mathrm{Eu}^{3+}$ - and $\mathrm{Er}^{3+} / \mathrm{Yb}^{3+}$-doped $\mathrm{GdVO}_{4}$ nanoparticles synthesized by reverse micelle method. Science and Reports, 4, 1-9. https://doi.org/10.1038/srep04209

46. Geßner, A. (2010). Lanthanoid-dotierte mikro- und Mesoporöse Feststoffe Charakterisierung von Ion-Wirt-Wechselwirkungen. University of Potsdam. 